\title{
Editorial for the special issue: "Advances and Trends in Post-transition Countries: Statistical Modelling Approach"
}

\author{
Ksenija Dumičić \\ Department of Statistics, Faculty of Economics and Business, University of \\ Zagreb, Zagreb, Croatia \\ Blagica Novkovska \\ Faculty of Economics, University of Tourism and Management, Skopje, \\ Republic of North Macedonia \\ Emina Resić \\ School of Economics and Business of University of Sarajevo, Bosnia and \\ Herzegovina
}

\section{Abstract}

This special issue of Business Systems Research is highlights recent advances and trends in post-transition countries, taking into account statistical modelling approach. Nine papers that have been selected for this special issue present improvements and new techniques (methodology) in statistical modelling and their use in various aspects of development in post-transition countries

Keywords: statistical modelling, post-transition countries

Citation: Dumičić, K., Novkovska, B., Resić, E. (2019). "Advances and Trends in Posttransition Countries: Statistical Modelling Approach", Vol. 10, No. 2, 1-5.

DOI: 10.2478/bsrj-2019-026

\section{Editorial process}

This special issue was organized with the goal to present the advances and trends in post-transition countries, which utilise the statistical modelling approach. The call was distributed among statistical modelling specialists in the South Eastern European countries. Nine papers were received, for which we believe that they will spark interest in the recent advances of statistical modelling. Included research papers move beyond a simple presentation of statistical concepts and present their lively presence and relevance in the context of post-transition countries. According to the goals and editorial policy, the selected papers are focusing to original theoretical and empirical advances in the area of statistical modelling. Some of the papers, but not all of them, were presented at the second International Statistical Conference in CroatiaISCCRO' 18, organized by the Croatian Statistical Association (CSA), which took place from the 10th May to the 11 th May 2018 in Opatija. The conference covered statistical topics and areas, but also similar and related areas and multidisciplinary fields. It provided a platform for international and national networking and exchange of ideas on various aspects of statistics and related professional and scientific areas and brought together researchers and practitioners from various aspects of statistical profession and science with the aim of establishing contacts, presenting scientific ideas and experiences. 
In the first paper, entitled "Analysis of Higher Education Indicators Coherency in Central and Eastern Europe", Andrejević Panić and Lozanov-Crvenković examine mutual interaction of higher education indicators, through formulating financial models that connect performance and financial indicators. A total of 4 higher education indicators were analysed and observed in the time period of 10 years in selected CEE countries. The statistical analysis was based on panel data models. The main result of the paper is the analysis of coherency of selected higher education indicators in selected CEE countries in order to establish functional links between government expenditure and efficiency through formulating financial models. Formulated financial models can predict the behavior of selected performance indicators, depending on financial indicators. Therefore, the obtained models can contribute to the efficient allocation of funds and comprehensive macro-level decision making assessments in higher education policy reforms.

The second paper, entitled "Foreign- Versus Domestic-Owned firms in the Predicament 'Cui bono?'", of authors Apostolov and Domenico Scagnelli, examine the productivity of domestic firms in the case of the foreign ownership. Foreign direct investments affect the competitive competences of domestic firms; thus, the objective is to see the way foreign ownership drives the growth of domestic firms. The study uses standard models to analyse productivity; they are applied to data sets of Macedonia, a Southeast European economy, and it is concluded that foreign ownership has a major role in domestic firms' restructuring processes increasing their productivity. Surely, the results support the principal notion that the augmented presence of foreign firms is to influence the restructuring and business activity of domestic companies positively. Our analysis verifies that foreign ownership has influenced the overall economy and particularly domestic-owned firms with the constant increase in employment and especially direct export.

In the third paper, entitled "Determinants of Tax Morale in Croatia: an Ordered Logit Model", Bejaković and Bezeredi investigate determinants that shape tax morale of Croatian citizens. An ordered logit model is employed to evaluate which determinants shape tax morale of Croatian citizens. Data for the research were collected from 2,000 face-to-face interviews conducted in Croatia in late 2015. The descriptive analysis illustrates that 52 percent of respondents reported a high level of tax morale, 26 percent of respondents have a low tax morale, while 8 and 14 percent have a midlow and a mid-high tax morale, respectively. The ordered logit analysis revealed that gender, age, financial situation, region, and participation in the unofficial economy have an impact on the tax morale. Besides socio-demographic, socio-economic, and spatial determinants, a great number of sanctions for participation in informal activities also shapes tax morale of the Croatian citizens. More precisely, marginal effects show that those perceiving the expected sanctions as "normal tax or social security contributions due, plus a fine or a prison sentence" have by 6.3 percentage points higher probability of reporting the highest tax morale than others.

In the next paper, entitled "Impact of Internal Migration on Population Redistribution in Slovenia", Drobne and Drešček suggest that in most countries, data on migration refer only to flows between administratively or statistically defined zones that are changing over time. When different numbers, sizes, and shapes of areas are chosen for analysis of internal migration, different results are generated. This problem is recognised as the Modifiable Areal Unit Problem (MAUP). The paper analyses the impact of inter-municipal migration on population redistribution in Slovenia in 2000 2014 by considering the MAUP. Namely, the number of analysed municipalities increased by 19 in the considered period. We analysed the MAUP effects and estimated internal migration statistics by producing a large number of aggregations 
using the IMAGE Studio software. Several statistics that measure the direction and pace of population concentration, as well as the correlation between measures of migration intensity and national development, have been calculated. The results for Slovenia show that the migration efficiency decreases with the development process measured by the human development index.

In the fifth paper, entitled "Measurement of Export Market Concentration for the Largest European Economic Integrations", Jošić, Žmuk and Dumičić discuss that by joining different regional economic trade agreements, countries achieve preferential trade liberalisation. There are four main types of regional economic agreements in the world today: free trade area, customs union, common market, and economic and monetary union. The goal of this paper is the measurement of the export market concentration for the largest European regional economic integrations in the period between 1995 and 2016. Various concentration measures have been used in the measurement of export market concentration, but the emphasis is placed on the standardized Herfindahl-Hirschman index as the basic measure of trade concentration. Results of the analysis have shown that the highest concentration level of trade with countries worldwide is among the European Free Trade Association (EFTA) countries, whereas the EU-15 countries seem to have the lowest concentration level. On the other side, the Central European Free Trade Agreement (CEFTA) countries have the highest concentration level of trade with countries from the same group, and again the EU-15 countries have the lowest concentration level, which indicates that the CEFTA countries implemented deeper integration processes related to mutual intra-regional trade. Deep integration processes led to lower values of export market concentration indices for intra-regional trade among countries of the same regional economic integration in comparison to trading with countries worldwide.

The sixth paper, entitled "Shedding Light on the Doing Business Index: a Machine Learning Approach", of authors Maričić, Bulajić, Radojičić and Jeremić, highlights that The World Bank (WB) acknowledged the importance of business regulatory environment and therefore created a metric which ranks 190 countries based on their level of business regulation for domestic firms measured by the Doing Business Index (DBI). The question which attracted our attention is whether all the observed entities should be given the same weighting scheme. The approach we propose as an answer is two-fold. First, we cluster the countries covered by the DBI. In the next step, we apply the statistical multivariate Composite I-distance Indicator (CIDI) methodology to determine new, data-driven weights for each of the retained clusters. The obtained results show that there is a difference between the weighting schemes proposed by the CIDI methodology. One can argue that one weighting scheme does not fit all the observed countries, meaning that additional analyses on the DBI are suggested to explore its stability and its weighting scheme.

The seventh paper, entitled "Achieving Portfolio Diversification through Cryptocurrencies in European Markets", of authors Pavković, Anđelinović and Pavković, outlines that cryptocurrencies represent a specific technological innovation in financial markets that keeps getting more and more popular among investors around the world. Given the specific characteristics of the cryptocurrencies, this paper examines the possibility of their use as a diversification instrument. This paper examines the direction and strength of the relationship between the selected cryptocurrencies and important financial indicators on the European Union market. Since cryptocurrencies are a novelty in the financial system, the empirical literature in this area is rather scarce. In order to assess diversification properties of cryptocurrencies for European traders, a comprehensive econometric analysis was carried out. The first 
part of the analysis refers to the estimation of the multivariate Generalized Autoregressive Conditional Heteroscedasticity (GARCH) model, whereas the second part focuses on wavelet transforms. Bitcoin and Ripple proved as a possible diversification instrument on most of the observed European markets since corresponding coefficients of unconditional correlation are negative. The relationship between the value of the cryptocurrencies and selected indices is generally very weak and slightly negative, indicating that some cryptocurrencies can serve as a means of diversification. However, investors need to take into account the extreme volatility, exhibited in all existing cryptocurrencies.

In the eighth paper, entitled 'Employers' Perceptions of Business and Economics Graduates' Competencies in Croatia", Štambuk, Karanović and Host discuss the issue of graduates' competencies is not a new one, but was brought back into the spotlight after the 2007-2008 Global Financial Crisis and the ensuing disturbances in the labour market. These disturbances were manifested through an increased unemployment rate, with a significant share of highly educated people. This paper provides an insight into employers' assessment of the importance and sufficiency of the competencies acquired by business and economics university bachelor graduates in Croatia. The methodology applied in this research includes the importance-performance analysis (IPA) that provides a two-dimensional importance-satisfaction grid. Data for the IPA analysis were collected by the structured questionnaire. Results indicated that employers are satisfied with specific competencies (business and economic) and that the emphasis of business and economics higher education institutions (HEI) should be placed on generic competencies. Findings imply that mobility of highly educated people could be caused by the level and quality of specific competencies of bachelors with a degree from Croatian economics higher education institutions. Additionally, the conclusion of the conducted study indicates a need for implementation of student-oriented teaching methods, the introduction of obligatory internship, and introduction of courses oriented towards the development of generic competencies.

In the last paper, entitled "Technology Acceptance Model for the Internet Banking Acceptance in Split", Vuković, Pivac and Kundid determine whether the motivation for using the Internet banking in the city of Split, Croatia, can be explained by perceived ease of use and perceived usefulness as the main elements of the technology acceptance model. For the purposes of the research, a survey analysis was applied to the sample of 282 working residents of Split. The gender and age structure of the sample was harmonized with the population to make the results more credible. In order to test the research hypothesis, logistic regression models were used. The results confirmed that both elements of the technology acceptance model significantly influence the acceptance of the Internet banking in the city of Split. It is concluded that demographic and economic characteristics and perception of individuals affect the acceptance and use of the Internet banking in the city of Split. The results showed that both elements of the technology acceptance model influence the acceptance of the Internet banking.

It might be concluded that the high quality papers of this special issue would be interesting to both, the scientific and the professional audience, since possible influence on theory and applications are visible. 


\section{About the editors}

Ksenija Dumičić, PhD, Full Tenured Professor at the Department of Statistics, Faculty of Economics and Business, University of Zagreb, specialized at the Institute for Social Research at University of Michigan, focusing on survey sampling, SQC and business statistics. She is founder and the leader of the first statistical postgraduate studies in Croatia. She led and participated in many projects granted by Ministry of Science in Croatia, World Bank, UNICEF, WHO, European Commission etc. She was President of Croatian Statistical Association, Editors-in-Chief for Croatian Review of Economic, Business and Social Statistics, founder of the International Statistical Conference in Croatia (ISCCRO), Elected Member at the International Statistical Institute (ISI), contributing to the IASS, IASE and CW-ISI, and member of the Royal Statistical Society. She published more than 180 publications. The author can be contacted at kdumicic@net.efzg.hr

Blagica Novkovska, PhD, is an Assistant Professor at the Faculty of Economics, University of Tourism and Management in Skopje. She offers more than 25 years of experience with official statistics, from which 10 years as General Director of the State Statistical Office. She is elected member of the International Statistical Institute and member of several international associations. She leaded more than $10 \mathrm{EU}$ funded projects in the field of official statistics. She co-authored 4 books and more than 40 research papers on: macroeconomic modelling, clustering, quality management, sustainable development, regional development and labour economics. The author can be contacted at b.novkovska@utms.edu.mk

Emina Resić is an associate professor at the School of Economics and Business, University of Sarajevo, B\&H. Her fields of interest are Statistics, Econometrics, Qualitative research methodology etc. She is author of many research and scientific papers. She can be contacted at emina.resic@efsa.unsa.ba 